\title{
A method linking the toxic effects at community-level with contaminant concentrations
}

\author{
Changyou Wang ${ }^{\mathrm{a}, \mathrm{d}, *}$, Rongguo Su ${ }^{\mathrm{b}}$, Yong Zhang ${ }^{\mathrm{c}}$, Gang Liu ${ }^{\mathrm{a}, \mathrm{d}}$ \\ a School of Marine Sciences, Nanjing University of Information Science and Technology, Nanjing 210044, China \\ b College of Chemistry and Chemical Engineering, Ocean University of China, Qingdao 266100, China

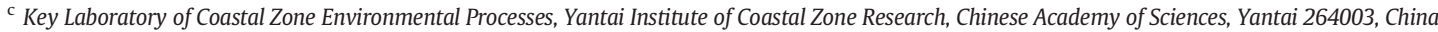 \\ d Jiangsu Research Center for Ocean Survey Technology, Nanjing University of Information Science and Technology, Nanjing 210044, China
}

\section{H I G H L I G H T S}

- We tested petroleum hydrocarbon ecotoxicological effects on a simplified community.

- Concentration-response relationships at a community-level were constructed.

- A deduced no-effect concentration representing ecological interaction was named TCPE.

- TCPE of petroleum hydrocarbons was higher than PNEC calculated from SSD.

- Ecological interactions reduce toxic effect of petroleum hydrocarbons on a community.

\section{G R A P H I C A L A B S T R A C T}

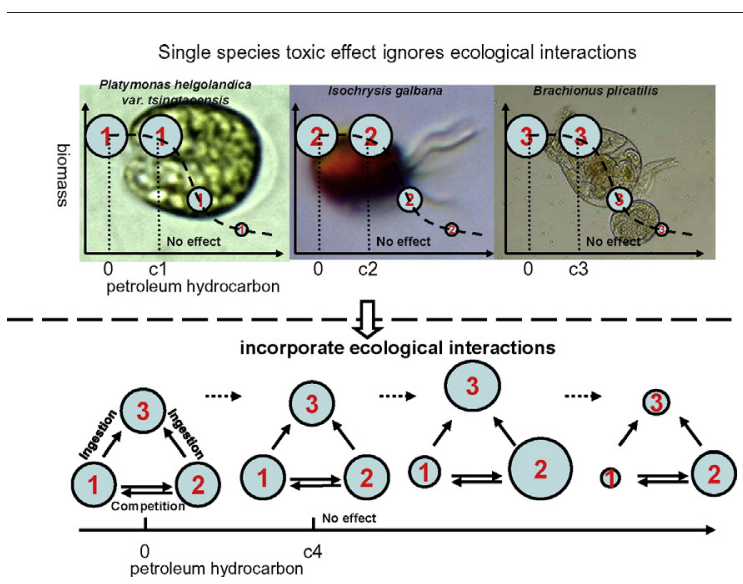

A B S T R A C T

In this study, we developed a method to quantify and link the toxic effects in community-level ecosystems with concentrations of petroleum hydrocarbons. The densities of Platymonas helgolandica var. tsingtaoensis, Isochrysis galbana, and Brachionus plicatilis in single-species tests and customized ecosystems were examined in response to a concentration gradient of petroleum hydrocarbons ranging from 0 to $8.0 \mathrm{mg} \mathrm{L}^{-1}$. A three-population ecological model with interspecies competition-grazing relationships was used to characterize population sizes with concentrations of petroleum hydrocarbons. A threshold concentration of the simplified plankton ecosystem of $0.376 \mathrm{mg} \mathrm{L}^{-1}$ for petroleum hydrocarbons was calculated from the proposed model, which was higher than the no-effect concentration of $0.056 \mathrm{mg} \mathrm{L}^{-1}$ derived from the single-species toxicity tests and the predicted no-effect concentration of $0.076 \mathrm{mg} \mathrm{L}^{-1}$ calculated from the species sensitivity distribution. This finding indicates that interspecies competition and grazing reduced the toxic effect of petroleum hydrocarbons at the community level. The sensitivity analysis for model parameters demonstrates that plankton population biomasses are highly sensitive to filtration rates. Antagonism between interspecies interactions and petroleum hydrocarbon toxicity was attributed to the reduced filtration rate and zooplankton grazing pressure. The proposed method is a simple

\footnotetext{
* Corresponding author at: School of Marine Sciences, Nanjing University of Information Science and Technology, Nanjing 210044, China.
} 
means to address the concern regarding the impacts of ecological interactions on ecological risk assessments of pollutants.

(c) 2016 Elsevier B.V. All rights reserved.

\section{Introduction}

Over a million tonnes of crude oil have been released into the ocean owing to human economic activities in the past 40 years (ITOPF, 2013). One of the major constituents of crude oil is petroleum hydrocarbons, which produce toxic effects on marine plankton and cause catastrophic damage to the marine environment (Wang et al., 2015a, 2015b). This environmental issue has received enormous attention worldwide. The protection of marine ecosystems relies on accurate understanding and scientific assessment of the effects of oil pollutants. The majority of existing assessments concerning the ecotoxicological effects of pollutants on the structures and functions of ecosystems depend on the extrapolation of single-species effect data to community-level effects (Laender et al., 2008). One of the most sophisticated extrapolation methods, the species sensitivity distribution (SSD), assumes that the sensitivity of an ecosystem can be represented by a set of independent species sensitivities obtained from single-species toxicity tests and the ecological threshold concentrations of all the species in a community follow some form of probability distribution (Laender et al., 2008; Van, 2004). One of the most common approaches that risk managers use to account for any uncertainties or variability in extrapolation is to apply an assessment factor (i.e., a numerical adjustment), which assumes that the factors from 10 to 100 can sufficiently protect the ecosystem (European Commission, 2003; Lau et al., 2013). However, such assumptions ignore the ecological relationships among community populations. The toxic effects on ecosystems at the community-level have been found to be determined by the inherent sensitivities of the species present and the ecological relationships between these species (Chapman et al., 2003; Fleeger et al., 2003; Laender et al., 2008). Therefore, the ecological interactions within communities should be considered during ecological effect assessments to provide accurate estimations of the effects of pollutants (Laender et al., 2008).

Large-scale experimental studies are complex and expensive, and their reproducibility is low, making them unsuitable for routine practices. Therefore, the development of other methodologies that require fewer resources to extrapolate single-species toxic effect data to ecosystem-level responses is necessary. Ecosystem models can be used as alternative, practical solutions to these extrapolation problems. However, the results obtained by ecosystem models are difficult to validate with experimental data having multi-trophic levels (Meng et al., 2009). One model, the simplified ecosystem model, has few parameters (only the first and second trophic levels are used); thus, it can be validated by ecological experiments. Simplified models are promising as ecotoxicology research tools because they incorporate the essential constituents and principal ecological relationships in ecosystems (Feng, 2006; Steele, 1974; Tang, 1999; Xu, 2008). In the present study, the toxic effects of petroleum hydrocarbons at the community-level were examined using a simplified ecological scenario consisting of representative species of Platymonas helgolandica var. tsingtaoensis, Isochrysis galbana, and Brachionus plicatilis from coastal waters of China. The data sets obtained were used to parameterize a plankton ecosystem model with interspecies competition-grazing relationships, which was proposed to quantify and link the toxic effects in communitylevel ecosystems with the concentrations of petroleum hydrocarbons. In addition, a new indicator representing interspecies interactions was introduced to assess the ecological effects of petroleum hydrocarbons on ocean ecosystems.

\section{Materials and methods}

\subsection{Plankton species and petroleum hydrocarbon used in experiment}

The selection of experimental plankton species referred to an approach for the development of ecological scenarios (Rico et al., 2016), with representative and functional species expected to be impacted by petroleum hydrocarbon exposure considered. P. helgolandica var. tsingtaoensis and I. galbana are planktonic single cell algae found widely in coastal waters of the China Sea, especially in mariculture regions. They can be rapidly cultured and are nutritious for marine animal larvae of economic value, acting as a basic food source. Detailed information exists in the literature on their response to culture conditions, including light, temperature, salinity, and nutrients, and they have been extensively and successfully cultured in laboratories and aquafarms (Hao et al., 2008; Sun et al., 2005). The rotifer B. plicatilis occurs worldwide, is extensively found in coastal waters, and is an adequate first feed for larval rearing of marine fish. The adaptable B. plicatilis propagates rapidly, having a short life cycle, and its dormant eggs can be commercially obtained (Fang et al., 2013). B. plicatilis is often used as a test organism in environmental monitoring and ecotoxicology studies (Fang et al., 2013; OECD, 2002; Snell and Janssen, 1995). For these reasons, P. helgolandica var. tsingtaoensis, I. galbana, and B. plicatilis were chosen as the experimental species in the present study.

The water-accommodated fractions of crude oil collected from the SZ36 oil well in Bohai, China were prepared for the petroleum hydrocarbon solution used in this study. The crude oil sample contained $0.2 \%$ sulfur, $0.4 \%$ nitrogen, $11.6 \%$ hydrogen, and $87.6 \%$ carbon in element composition of organics, and $2.8 \%$ paraffin, $21.4 \%$ colloid, $2.0 \%$ asphaltene, $0.3 \%$ water, $0.02 \%$ ash, $9.0 \%$ carbon residue, and $63 \%$ sodium chloride in chemical composition, placing it in the low sulfur naphthene base oil category.

The petroleum hydrocarbon concentrations in the prepared solution were measured by ultraviolet spectrophotometry (UV-2102PCS, Unico (Shanghai) Instrument Co., Ltd.) at $225 \mathrm{~nm}$. The analytical limit of detection was $0.002 \mathrm{mg} \mathrm{L}^{-1}$ and the average relative standard deviation was $<2 \%$. The experiments were performed and controlled according to the Chinese standard GB/T 21805-2008 (General Administration of Quality Supervision, Inspection and Quarantine of China, 2008) and (ASTM E1440-91, (2012).

\subsection{The toxic effects on phytoplankton}

\subsubsection{Algal single-species tests}

The algae ( $P$. helgolandica var. tsingtaoensis and I. galbana) were cultivated in three 1-L conical flasks containing natural, filtered $(<20 \mu \mathrm{m})$ autoclaved seawater. The seawater was obtained from the East China Sea near Qidong County, where the salinity was approximately 30 psu. Nitrate, phosphate, vitamins, and trace elements were added in accordance with the $\mathrm{f} / 2$ medium recipe (Guillard and Ryther, 1962). The conical flasks were placed in an incubator at a constant temperature of $23^{\circ} \mathrm{C}$ for a photoperiod of $12 \mathrm{~h}$ light and $12 \mathrm{~h}$ dark, and a photon irradiance of approximately $60 \mu \mathrm{mol} \mathrm{m} \mathrm{m}^{-2} \mathrm{~s}^{-1}$ (Wang et al., 2010). The initial algal incubation density was $5 \times 10^{6}$ cells $\mathrm{mL}^{-1}$ for $P$. helgolandica var. tsingtaoensis and $12 \times 10^{6}$ cells $\mathrm{mL}^{-1}$ for I. galbana. The concentrations of the petroleum hydrocarbons for the toxicity tests were $0,0.2,0.4,0.8$, $1.2,2.0,4.0$, and $8.0 \mathrm{mg} \mathrm{L}^{-1}$, which were determined in a preliminary experiment. The algal single-species toxicity tests ran for up to 16 days until maximum densities were approached or attained. During 


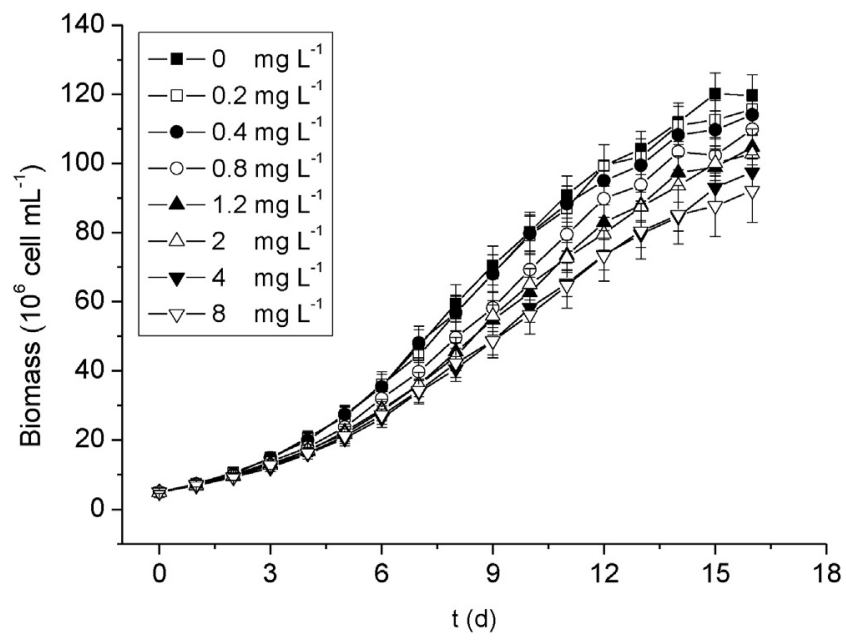

Fig. 1. Biomasses changes of Platymonas helgolandica var. tsingtaoensis over time at different concentrations of petroleum hydrocarbon.

the experimental period, $5 \mathrm{~mL}$ water samples were extracted from the culture flasks every day and fixed with Lugol's solution. The algae species composition and cell numbers in the samples were determined by light microscopy (XLE-2, 3DFAMILY Technology Co., Ltd., Nanjing, China); the measurements were replicated three times.

\subsubsection{Algal bi-species competition test}

In the bi-species algal competition experiment, the initial algal incubation densities were $5 \times 10^{6}$ cells $\mathrm{mL}^{-1}$ for $P$. helgolandica var. tsingtaoensis and $12 \times 10^{6}$ cells $\mathrm{mL}^{-1}$ for I. galbana, which were the same biomass values as those determined using their single cell volumes (Li and Wang, 2012). The culture conditions, experimental design and duration, and concentration gradient of the petroleum hydrocarbons were consistent with those for the algal single-species tests.

\subsection{The toxic effects on zooplankton}

\subsubsection{Rotifer test for mortality rate}

The zooplankton rotifer B. plicatilis was cultured in 6-well culture plates containing $5 \mathrm{~mL}$ of culture solution. The larvae, which were incubated simultaneously, were placed in the culture plates, with one larva per well. The culture plates were placed in an incubator at a constant temperature of $23{ }^{\circ} \mathrm{C}$ for a photoperiod of $12 \mathrm{~h}$ light and $12 \mathrm{~h}$ dark, and a photon irradiance of approximately $60 \mu \mathrm{mol} \mathrm{m} \mathrm{m}^{-2} \mathrm{~s}^{-1}$. The larvae were fed every $24 \mathrm{~h}$ with $0.2 \mathrm{~mL}$ of Chlorella sp. algae at a density of $1 \times 10^{6}$ cells $\mathrm{mL}^{-1}$. Observations of each $B$. plicatilis were taken every $3 \mathrm{~h}$. After recording the appearance of first eggs and the hatching time of the first larvae, the observations were taken every 6 h (Feng, 2006). The number of eggs laid, number of incubated larvae, and survival times of B. plicatilis were recorded simultaneously, and were later used to calculate one of the parameters (the mortality rate of $B$. plicatilis) in the simplified plankton ecosystem model. After the measurements were taken, the larvae were removed from the culture solution. The experiment continued until all of the observed B. plicatilis died.

\subsubsection{Rotifer test for filtration rates}

The simultaneously incubated rotifer larvae were fed either $P$. helgolandica var. tsingtaoensis or I. galbana for three days, and then not fed for one day before the ingestive behavior experiment was conducted. The unfed larvae were placed in $150-\mathrm{mL}$ conical flasks containing $50-\mathrm{mL}$ algal solutions of different densities (Feng, 2006). The test concentrations of the petroleum hydrocarbons were the same as for the algal tests described in Sections 2.2.1 and 2.2.2. The conical flasks were placed in a carton covered with black cloths, then placed on a controlled temperature oscillator for $24 \mathrm{~h}$. The algal cell densities were determined by light microscopy before and after ingestion. Using the equations proposed by Frost (1972), the filtration and ingestion rates for the test concentrations of petroleum hydrocarbons were calculated by the differences in the density of algae between the control and the treatments containing rotifers.

\subsection{The toxic effects on the simplified plankton ecosystem}

The initial algal incubation densities of $P$. helgolandica var. tsingtaoensis and I. galbana in the simplified plankton ecosystem experiments were $5 \times 10^{6}$ cells $\mathrm{mL}^{-1}$ and $12 \times 10^{6}$ cells $\mathrm{mL}^{-1}$, respectively. In addition, the initial density of the rotifer $B$. plicatilis was 5 individuals $\mathrm{mL}^{-1}$. The two algae species had equal initial biomasses, which were determined using their single cell volumes (Li et al., 2011; Li and Wang, 2012; Wang et al., 2010). The initial rotifers were selected from moving individuals cultured under identical conditions. The experiment was conducted in a 1-L conical flask with $0.5 \mathrm{~L}$ of culture solution and was replicated three times for each concentration gradient of the pollutant. The test concentrations of the petroleum hydrocarbons in this experiment were the same as for the algal tests described in Sections 2.2.1 and 2.2.2, as were the culture conditions. The densities of the rotifers and algae were determined each day by light microscopy (XLE-2, 3DFAMILY Technology Co., Ltd., Nanjing, China). The duration of the experiment depended on the occurrence of the stable plankton populations.

\subsection{Model construction}

A simplified plankton ecological model was constructed by integrating the logistic growth equation and the Lotka-Volterra equation into a competition-grazing model (Volterra, 1926; Wang et al., 2011). In addition, algal density restrictions were accounted for in the model. The simplified plankton ecological model equations are provided below:

$\frac{d P_{1}}{d t}=P_{1}\left(r_{1}-a_{11} P_{1}-a_{12} P_{2}-a_{13} Z\right)$

$\frac{d P_{2}}{d t}=P_{2}\left(r_{2}-a_{21} P_{1}-a_{22} P_{2}-a_{23} Z\right)$

$\frac{d Z}{d t}=\mathrm{Z}\left(-r_{3}+a_{31} P_{1}+a_{32} P_{2}\right)$

In this model, $P_{1}$ represents the abundance of $P$. helgolandica var. tsingtaoensis, $P_{2}$ represents the abundance of I. galbana, and $\mathrm{Z}$ represents

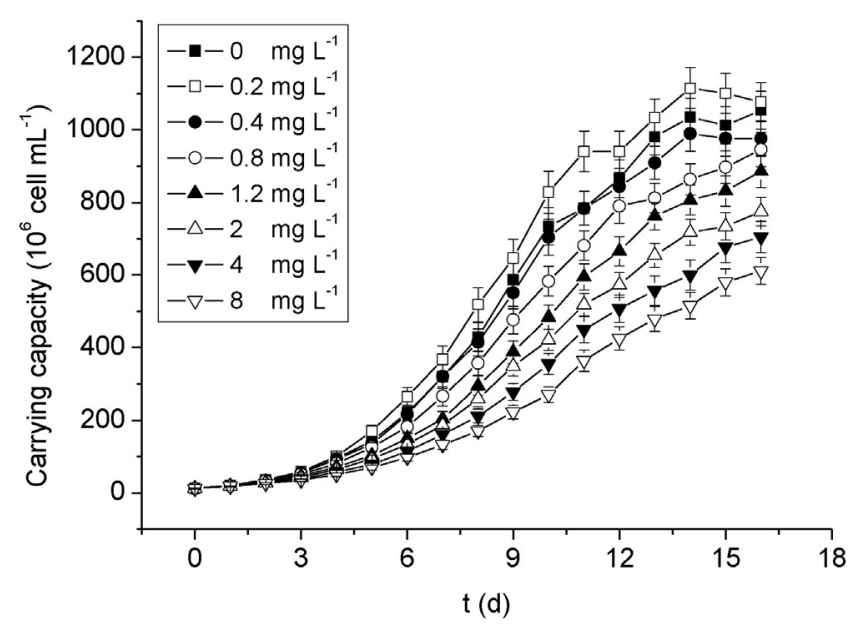

Fig. 2. Biomasses changes of Isochrysis galbana over time at different concentrations of petroleum hydrocarbon. 


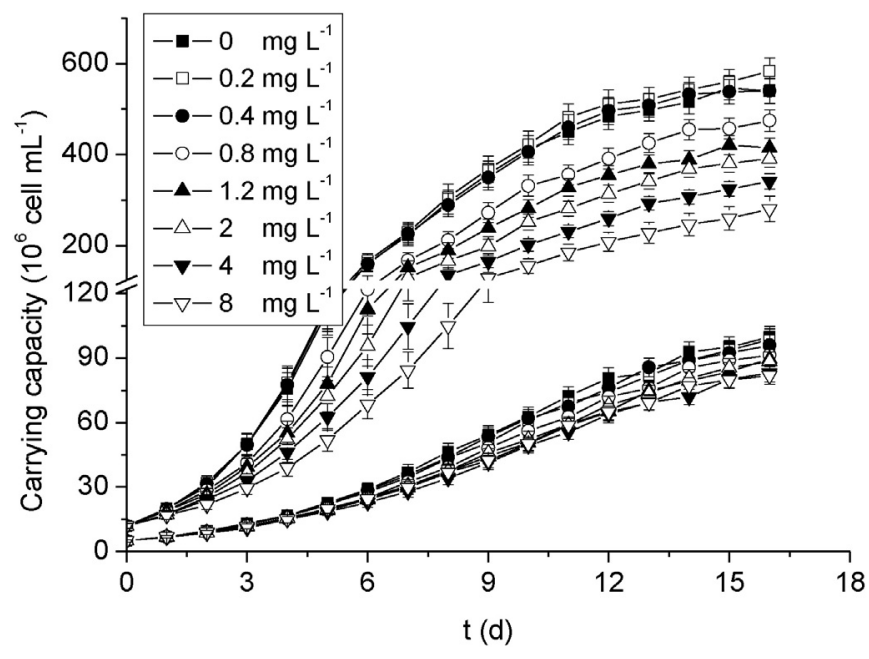

Fig. 3. Biomasses changes of Platymonas helgolandica var. tsingtaoensis and Isochrysis galbana over time at different concentrations of petroleum hydrocarbon in bi-algae competitory experiment.

the abundance of the rotifer $B$. plicatilis. In addition, $r_{i}(i=1,2)$ denotes the instantaneous growth rate under the experimental conditions, with 1 representing $P$. helgolandica var. tsingtaoensis, and 2 representing $I$. galbana, while $r_{3}$ represents the instantaneous mortality rate of the rotifer B. plicatilis. Furthermore, $a_{11}=\frac{r_{1}}{K_{1}}, a_{12}=\frac{\alpha \cdot r_{1}}{K_{1}}, a_{13}=F_{1}, a_{21}=\frac{\beta \cdot r_{2}}{K_{2}}, a_{22}$ $=\frac{r_{2}}{K_{2}}, a_{23}=F_{2}, a_{31}=F_{1} \cdot h_{1}$, and $a_{32}=F_{2} \cdot h_{2}$, where $K_{i}(i=1,2)$ denotes the carrying capacity of the algae, $\alpha$ is the interspecific competition parameter for $P$. helgolandica var. tsingtaoensis, $\beta$ is the interspecific competition parameter for I. galbana, and $F_{i}(i=1,2)$ is the filtration rate from zooplankton to algae $(i)$.

According to the non-linear dynamic results of the ecosystem model, the simplified plankton ecological model only yields a positive asymptotic equilibrium point, $E^{*}\left(P_{1}{ }^{*}, P_{2}{ }^{*}, Z^{*}\right)$, when the plankton biomass and model coefficient matrix are consistently $>0$, indicating that the customized plankton ecosystem would continuously survive.

$P_{1} *=\frac{a_{12} a_{23} r_{3}+a_{13} r_{2} a_{32}-r_{1} a_{23} a_{32}-a_{13} a_{22} r_{3}}{a_{12} a_{23} a_{31}+a_{13} a_{21} a_{32}-a_{11} a_{23} a_{32}-a_{13} a_{22} a_{31}}$

$P_{2} *=\frac{r_{1} a_{23} a_{31}+a_{13} a_{21} r_{3}-a_{11} a_{23} r_{3}-a_{13} r_{2} a_{31}}{a_{12} a_{23} a_{31}+a_{13} a_{21} a_{32}-a_{11} a_{23} a_{32}-a_{13} a_{22} a_{31}}$

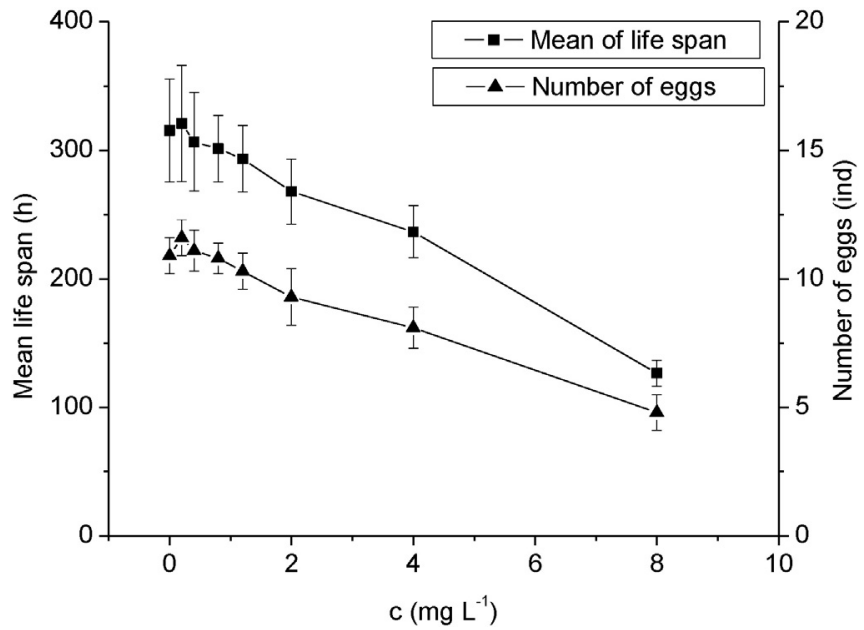

Fig. 4. Changes of life span and number of laid eggs per Brachionus plicatilis with concentrations of petroleum hydrocarbon.

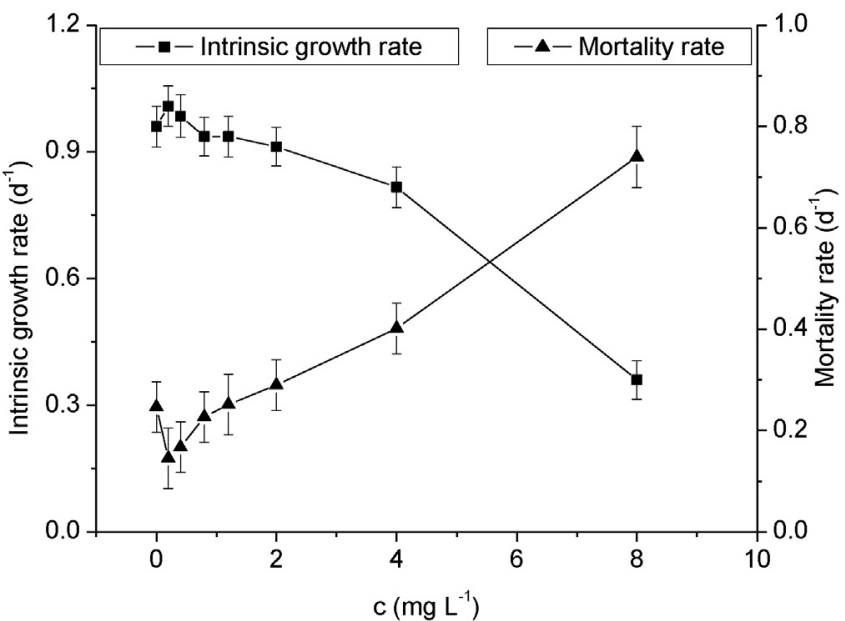

Fig. 5. Changes of intrinsic growth rate and mortality rate of Brachionus plicatilis population with concentrations of petroleum hydrocarbon.

$Z *=\frac{a_{11} a_{22} r_{3}+a_{12} r_{2} a_{31}+r_{1} a_{21} a_{32}-a_{11} r_{2} a_{32}-a_{12} a_{21} r_{3}-r_{1} a_{22} a_{31}}{a_{12} a_{23} a_{31}+a_{13} a_{21} a_{32}-a_{11} a_{23} a_{32}-a_{13} a_{22} a_{31}}$

The equilibrium point values diverged from the original equilibrium point as the pollutant concentrations increased. In the experiment, the maximum pollutant concentration where the equilibrium point did not diverge from the original, i.e., was not significantly different, was defined as the threshold concentration. A hypothesis test approach based on the $t$-test was used to compare the abundances of equilibrium points at the different pollutant concentrations with those in the control group to determine whether divergence occurred. MATLAB 2008b software was used to perform all calculations.

\subsection{The parameters in the plankton ecosystem model}

The growth rates $\left(r_{1}\right.$ and $\left.r_{2}\right)$ and carrying capacities $\left(K_{1}\right.$ and $\left.K_{2}\right)$ of the phytoplankton were calculated using a combination of the logistic growth model and the experimental data obtained from the algal single species experiment (Wang et al., 2011). The interspecies competition coefficients ( $\alpha$ and $\beta$ ) of the phytoplankton were calculated using the Lotka-Volterra competition model and the experimental data obtained

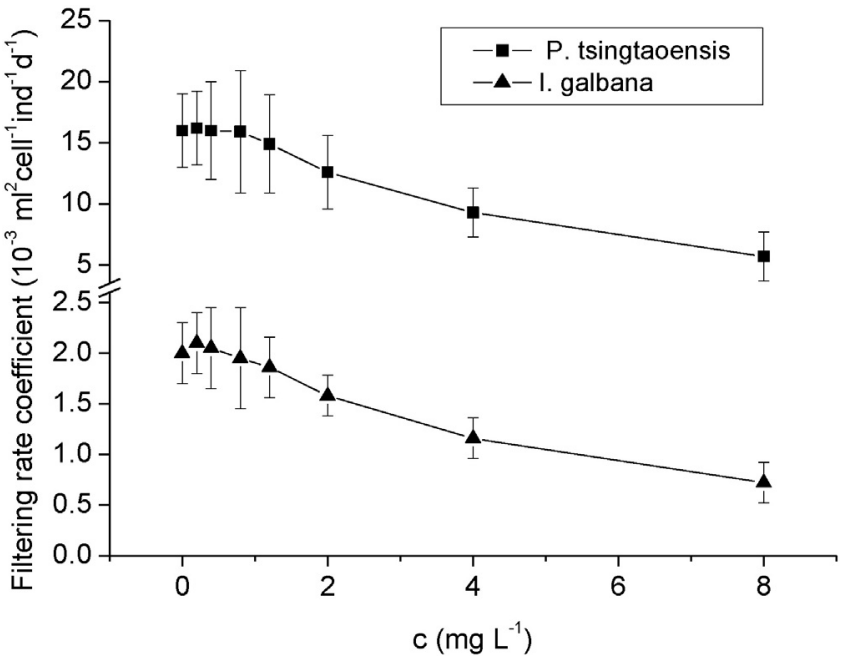

Fig. 6. Changes of filtering rate coefficient of Brachionus plicatilis for Platymonas helgolandica var. tsingtaoensis and Isochrysis galbana with concentrations of petroleum hydrocarbon. 
Table 1

Model parameters in unexposed simplified plankton ecosystem.

\begin{tabular}{|c|c|c|}
\hline $\begin{array}{l}\text { Parameter } \\
\text { symbol }\end{array}$ & Description & $\begin{array}{l}\text { Average } \\
\text { (standard } \\
\text { deviation) }\end{array}$ \\
\hline$r_{01}$ & $\begin{array}{l}\text { Growth rate of Platymonas helgolandica var. } \\
\text { tsingtaoensis }\left(\mathrm{d}^{-1}\right) \text { in control }\end{array}$ & $0.37(0.01)$ \\
\hline$r_{02}$ & Growth rate of Isochrysis galbana $\left(\mathrm{d}^{-1}\right)$ in control & $0.52(0.02)$ \\
\hline $\mathrm{K}_{01}$ & $\begin{array}{l}\text { Carrying capacity of Platymonas helgolandica var. } \\
\text { tsingtaoensis }\left(10^{6} \text { cells } \mathrm{mL}^{-1}\right) \text { in control }\end{array}$ & $122.88(2.16)$ \\
\hline $\mathrm{K}_{02}$ & $\begin{array}{l}\text { Carrying capacity of Isochrysis galbana }\left(10^{6} \text { cells }\right. \\
\left.\mathrm{mL}^{-1}\right) \text { in control }\end{array}$ & $1021.73(40.62)$ \\
\hline$\alpha$ & $\begin{array}{l}\text { Interspecific competition coefficient of Platymonas } \\
\text { helgolandica var. tsingtaoensis }\end{array}$ & $0.028(0.014)$ \\
\hline$\beta$ & $\begin{array}{l}\text { Interspecific competition coefficient of Isochrysis } \\
\text { galbana }\end{array}$ & $4.5(0.3)$ \\
\hline$r_{03}$ & $\begin{array}{l}\text { Mortality rate of Brachionus plicatilis }\left(\mathrm{d}^{-1}\right) \text { in } \\
\text { control }\end{array}$ & $0.25(0.05)$ \\
\hline $\mathrm{Fa}_{01}$ & $\begin{array}{l}\text { Filtering rate coefficient for Platymonas } \\
\text { helgolandica var. tsingtaoensis }\left(\mathrm{mL}^{2} \text { cell }\right. \\
\left.\mathrm{d}^{-1}\right) \text { in control }\end{array}$ & $0.016(0.003)$ \\
\hline $\mathrm{F}_{\mathrm{a} 02}$ & $\begin{array}{l}\text { Filtering rate coefficient for Isochrysis galbana } \\
\left(\mathrm{mL}^{2} \text { cell }^{-1} \text { ind }^{-1} \mathrm{~d}^{-1}\right) \text { in control }\end{array}$ & $0.002(0.0003)$ \\
\hline $\mathrm{W}_{1}$ & $\begin{array}{l}\text { Dry weight of Platymonas helgolandica var. } \\
\text { tsingtaoensis ( } \mathrm{pg} \mathrm{cell}^{-1} \text { ) }\end{array}$ & $47.9(3.4)$ \\
\hline $\mathrm{W}_{2}$ & Dry weight of Isochrysis galbana (pg cell ${ }^{-1}$ ) & $20.4(1.5)$ \\
\hline $\mathrm{W}_{3}$ & Dry weight of Brachionus plicatilis ( $\mu$ ind $^{-1}$ ) & $0.28(0.03)$ \\
\hline $\mathrm{h}_{1}$ & $\begin{array}{l}\text { Transfer efficiency from Platymonas helgolandica } \\
\text { var. tsingtaoensis biomass to Brachionus plicatilis } \\
\text { biomass (\%) }\end{array}$ & $20(5)$ \\
\hline $\mathrm{h}_{2}$ & $\begin{array}{l}\text { Transfer efficiency from Isochrysis galbana } \\
\text { biomass to Brachionus plicatilis biomass (\%) }\end{array}$ & $20(5)$ \\
\hline
\end{tabular}

from the algal bi-species competition experiment (Volterra, 1926). The filtration rate is proportional to the phytoplankton density when the phytoplankton density is relatively low (Wei, 2009). Therefore, the filtration rate $(\mathrm{F})$ is the product of the filtration rate coefficient $(\mathrm{Fa})$ and phytoplankton density. The $B$. plicatilis mortality rate $\left(r_{3}\right)$ and filtration rate coefficients $\left(\mathrm{Fa}_{1}\right.$ and $\left.\mathrm{Fa}_{2}\right)$ were calculated using the method introduced by Feng (2006) and Wei (2009) and the experimental data obtained from the $B$. plicatilis toxic effect experiment. The data relating to the dry weights $\left(\mathrm{W}_{1}, \mathrm{~W}_{2}\right.$, and $\left.\mathrm{W}_{3}\right)$ of the phytoplankton and zooplankton and the transfer efficiencies $\left(h_{1}\right.$ and $\left.h_{2}\right)$ from the former to the latter were obtained from the literature (Chen et al., 2007; Feng, 2006; Li et al., 2011) and calibrated within the range of collected data to gain a satisfactory fit.

To account for the variability in the test data, the sensitivities of parameters in the model were calculated using a Monte Carlo setting and characterized with coefficients of variation (CV) of plankton biomass at equilibrium points. The parameters varied within a range of $50 \%$ of their averages. While the sensitivity was calculated for a parameter, the others were kept constant. Only the sensitivity parameters were selected to describe the toxic effects with the modified Weibull function recommended by Wang et al. (2011). The modified Weibull functions, representing decreases in the values of sensitivity parameters with concentrations of petroleum hydrocarbons, were used as a toxic effect submodel in the simplified plankton ecosystem model:

$y=y_{0} e^{\left(-a\left(x^{b}-x_{0}^{b}\right)\right)}$

When characterizing the increase in mortality rate with increased concentrations of petroleum hydrocarbons, Eq. (7) should be replaced with Eq. (8):

$1-y=\left(1-y_{0}\right) e^{\left(-a\left(x^{b}-x_{0}^{b}\right)\right)}$

where $y$ and $y_{0}$ are the values of the parameter at a certain concentration of petroleum hydrocarbons and the control in the simplified plankton ecosystem model, respectively. $a$ and $b$ are the parameters of the Weibull model, $x$ is the concentration of petroleum hydrocarbons ( $\mathrm{mg} \mathrm{L}^{-1}$ ) and $x_{0}$ is the no-effect concentration at which $y$ does not show a significant difference from $y_{0}$. The no-detected toxic effect concentration (NDEC) with a 95\% confidence interval, proposed by Wang et al. (2011), was calculated by averaging $>200$ values of $x_{0}$ estimated with a nonlinear regression in a bootstrap procedure.

\subsection{Method for the calculation of threshold concentrations of petroleum hydrocarbons}

The parameters changed with the concentrations of petroleum hydrocarbons, which were expressed by the toxic effect sub-model, with these changes in parameters consequentially causing a variation in the outputs from the plankton ecosystem model. The Monte Carlo method was used to account for the variability of the obtained parameters. First, 1000 of the parameter data sets used in the simplified plankton ecosystem model were obtained with Latin hypercube sampling. Typically, it was found that the standard deviations of all parameters stabilized after 100 samplings. Next, five data sets were randomly selected for replacement from the aforementioned 1000 parameter data sets. The concentration value $\left(c_{1}\right)$ was calculated by averaging 0 (no-effect concentration) and $c_{0}$ (a certain toxic effect concentration). Then, five simulations were conducted using the five randomly selected data sets at $c_{1}$. The results of every population biomass were compared to the corresponding reference experimental data (five control replications), and their significance values were determined using a two-sample $t$-test. $c_{2}$ was calculated by averaging $c_{1}$ and $c_{0}$ when $c_{1}$ was determined to be a no-effect concentration, or by averaging 0 and $c_{1}$ when $c_{1}$ was determined to be an effect concentration. Subsequently, five simulations were conducted using the five randomly selected data

Table 2

Sensitivity for parameters characterized with coefficients of variation of plankton biomasses in equilibrium points.

\begin{tabular}{|c|c|c|c|c|c|c|}
\hline \multirow[b]{2}{*}{ Parameter } & \multirow[b]{2}{*}{ Average } & \multirow[b]{2}{*}{ Range } & \multicolumn{4}{|l|}{$\mathrm{CV}$} \\
\hline & & & Platymonas helgolandica var. tsingtaoensis & Isochrysis galbana & Brachionus plicatilis & equilibrium point \\
\hline $\mathrm{F}_{\mathrm{a} 1}$ & 0.016 & $0.008-0.024$ & 0.88 & 0.06 & 0.06 & 0.09 \\
\hline $\mathrm{F}_{\mathrm{a} 2}$ & 0.002 & $0.001-0.003$ & 0.27 & 0.46 & 0.37 & 0.45 \\
\hline $\mathrm{h}_{1}$ & 0.2 & $0.1-0.3$ & 0.03 & 0.03 & 0.03 & 0.03 \\
\hline $\mathrm{h}_{2}$ & 0.2 & $0.1-0.3$ & 0.33 & 0.33 & 0.25 & 0.32 \\
\hline $\mathrm{K}_{1}$ & 12,288 & $6144-18,432$ & 0.0002 & 0.00003 & 0.00003 & 0.00004 \\
\hline$\alpha$ & 0.028 & $0.014-0.042$ & 0.00002 & 0.000004 & 0.000004 & 0.000004 \\
\hline $\mathrm{K}_{2}$ & 10,273 & $51,086.5-153,259.5$ & 0.0003 & 0.00005 & 0.0003 & 0.0001 \\
\hline$\beta$ & 4.5 & $2.25-6.75$ & 0.00003 & 0.000004 & 0.000004 & 0.000004 \\
\hline$r_{1}$ & 0.37 & $0.185-0.555$ & 0.47 & 0.07 & 0.07 & 0.08 \\
\hline$r_{2}$ & 0.52 & $0.26-0.78$ & 0.70 & 0.15 & 0.45 & 0.20 \\
\hline$r_{3}$ & 0.25 & $0.125-0.375$ & 0.30 & 0.30 & 0.41 & 0.31 \\
\hline $\mathrm{W}_{1}$ & 0.48 & $0.24-0.72$ & 0.03 & 0.03 & 0.03 & 0.03 \\
\hline $\mathrm{W}_{2}$ & 0.204 & $0.102-0.306$ & 0.33 & 0.33 & 0.25 & 0.32 \\
\hline $\mathrm{W}_{3}$ & 0.28 & $0.14-0.42$ & 0.29 & 0.29 & 0.41 & 0.31 \\
\hline
\end{tabular}


sets at $c_{2}$ again. The significance values between the simulations and reference experimental data were again determined, and $c_{3}$ was calculated. These steps were repeated until $\mathrm{c}_{\mathrm{m}}$ was determined to be a noeffect concentration and the difference between $\mathrm{c}_{\mathrm{m}-1}$ and $\mathrm{c}_{\mathrm{m}}$ was small enough to satisfy the required precision $(0.001$ was used in present study).

The confidence intervals of $c_{m}$ were estimated using a bootstrap technique. Applying the same methodology as described in the previous paragraph, another five data sets were randomly selected for replacement from 1000 parameter data sets, yielding $c_{\mathrm{m}}$. These procedures were conducted $n$ times, yielding $n \times c_{m}$ values. The average value of $c_{m}$ was calculated as the threshold concentration of the simplified plankton ecosystem (TCPE); its confidence interval was estimated using the resulting frequency distributions of the pseudo-values (the 2.5th and 97.5th percentile values).

\section{Results and discussion}

3.1. The toxic effects of petroleum hydrocarbons on plankton and sensitivity analysis for parameters

The experimental results showed that densities of $P$. helgolandica var. tsingtaoensis and I. galbana decreased in the whole with increasing concentrations of petroleum hydrocarbons in the single alga test, as can be seen in Figs. 1 and 2, while I. galbana showed a greater decrease in density than $P$. helgolandica var. tsingtaoensis in the bi-species algal experiment (Fig. 3), indicating a competitive disadvantage. The petroleum hydrocarbon-related exposures also caused a clear reduction in the life span of $B$. plicatilis, number of eggs laid, intrinsic growth rate, and filtration rate coefficient when concentrations were above $1.2 \mathrm{mg} \mathrm{L}^{-1}$ (Figs. 4-6). From the data measured in this study, the parameters used in the simplified plankton ecosystem were calculated and are listed in Table 1.

The results of the sensitivity analysis for parameters indicated that the population biomass were sensitive to the $P$. helgolandica var. tsingtaoensis filtration rate $\left(\mathrm{Fa}_{1}\right)$ and the I. galbana growth rate $\left(r_{2}\right)$, which had CV values that were higher than 0.7 (Table 2). Following was the P. helgolandica var. tsingtaoensis growth rate $\left(r_{1}\right)$, with a CV value of approximately 0.5 . However, the filtration rate coefficient of $I$. galbana $\left(\mathrm{Fa}_{2}\right)$, transfer efficiency from I. galbana biomass to B. plicatilis biomass $\left(\mathrm{h}_{2}\right)$, mortality rate of $B$. plicatilis $\left(r_{3}\right)$, dry weight of I. galbana $\left(\mathrm{W}_{2}\right)$, and dry weight of $B$. plicatilis $\left(\mathrm{W}_{3}\right)$ were less influential, with $\mathrm{CV}$ values of approximately 0.3 . The carrying capacity of $P$. helgolandica var. tsingtaoensis $\left(\mathrm{K}_{1}\right)$, carrying capacity of I. galbana $\left(\mathrm{K}_{2}\right)$, interspecific competition coefficient of $P$. helgolandica var. tsingtaoensis $(\alpha)$, interspecific competition coefficient of I. galbana ( $\beta$ ), transfer efficiency from $P$.

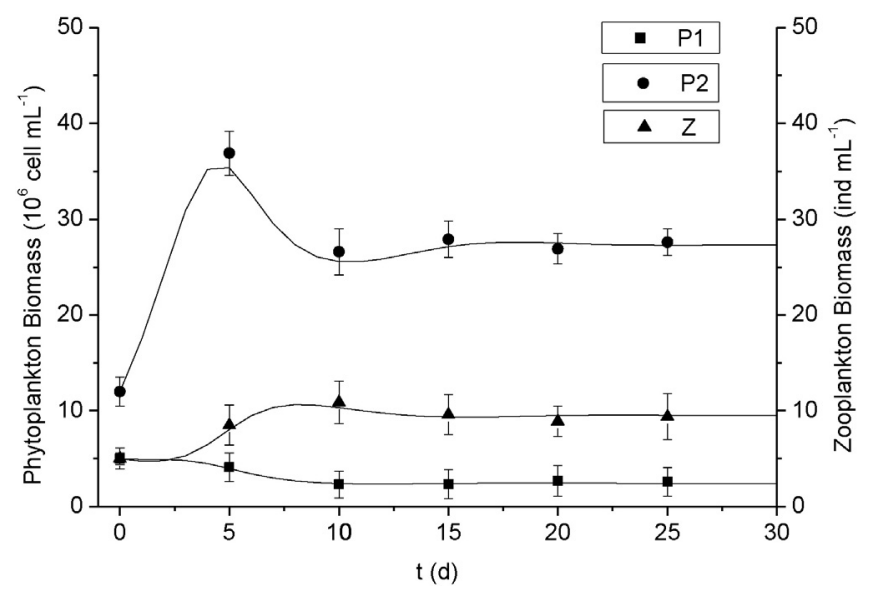

Fig. 7. Biomass changes in the unexposed simplified plankton ecosystem over time $\left(P_{1}\right.$ : Platymonas helgolandica var. tsingtaoensis; $P_{2}$ : Isochrysis galbana; $Z$ : rotifer Brachionus plicatilis). Scatter: experimental values; Line: simulated values.

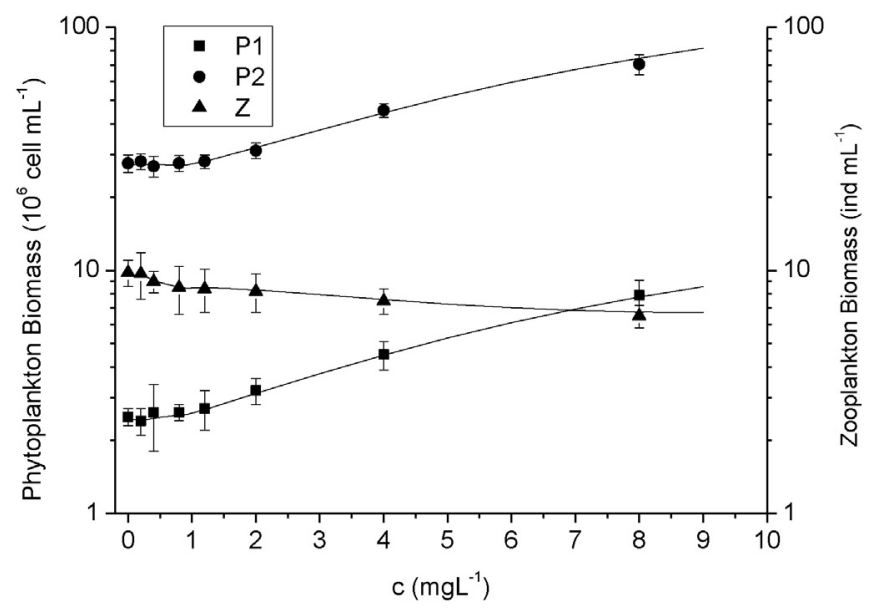

Fig. 8. Changes in the biomasses of the equilibrium points in the simplified plankton ecosystem with concentrations of petroleum hydrocarbon $\left(P_{1}\right.$ : Platymonas helgolandica var. tsingtaoensis; $P_{2}$ : Isochrysis galbana; $\mathrm{Z}$ : rotifer Brachionus plicatilis). Scatter: experimental values; Line: simulated values.

helgolandica var. tsingtaoensis biomass to $B$. plicatilis biomass $\left(h_{1}\right)$, and dry weight of $P$. helgolandica var. tsingtaoensis $\left(\mathrm{W}_{1}\right)$ were the least sensitive parameters, with $\mathrm{CV}$ values $<0.05$ (Table 2 ). These results indicate that the different parameters affected the excursion of the equilibrium point differently. Interestingly, the $\mathrm{CV}$ value for $\mathrm{h}_{2}$ was higher than that of $h_{1}$, suggesting that the contributions of the two algal species to the zooplankton biomasses were significantly different. As a parameter denoting algal maximum population density in the logistic growth model, carrying capacity was an insensitive parameter in the simplified plankton ecosystem, but has been proven to be more sensitive and reliable than the routine ecotoxicological endpoints in the single algal toxic effect test (Wang et al., 2011). This was owing to the fact that standing stocks of the plankton in the simplified plankton ecosystem were much lower than their carrying capacities, which would also account for the insensitivity of $\alpha$ and $\beta$.

3.2. The ecotoxicological effects of petroleum hydrocarbons on the simplified plankton ecosystem

As shown in Fig. 7, the densities of the three populations in the unexposed plankton ecosystem fluctuated before day 15 and subsequently became stable at an equilibrium point. When exposed to petroleum hydrocarbons, the densities of algal populations at the equilibrium point showed an a priori unpredictable pattern, which increased with the concentration of petroleum hydrocarbons in the experiment concentration range. Contrary to the algae, densities of $B$. plicatilis at the equilibrium point decreased when concentrations of petroleum hydrocarbons were $>1.2 \mathrm{mg} \mathrm{L}^{-1}$ (Fig. 8).

The experimental observations are in agreement with simulation results from the exposed plankton ecosystem dynamics, where toxic effects were expressed by using the selected sensitivity parameters, $\mathrm{Fa}_{1}$, $\mathrm{Fa}_{2}, r_{1}, r_{2}, r_{3}, \mathrm{~K}_{1}$, and $\mathrm{K}_{2}$, as endpoints in the toxic effect sub-model

Table 3

Parameters in toxic effect sub-model.

\begin{tabular}{lllll}
\hline \multirow{2}{*}{ Toxic effects } & Endpoints & $\mathrm{a}$ & $\mathrm{b}$ & $\mathrm{x}_{0}\left(\mathrm{mg} \mathrm{L}^{-1}\right)$ \\
\cline { 3 - 5 } Growth effect & $\mathrm{K}_{1}$ & $0.132(0.004)$ & $0.325(0.007)$ & $0.056(0.002)$ \\
& $r_{1}$ & $0.869(0.079)$ & $0.065(0.008)$ & $0.233(0.031)$ \\
& $\mathrm{K}_{2}$ & $2.70(0.30)$ & $0.043(0.003)$ & $0.331(0.005)$ \\
Mortality effect & $r_{2}$ & $3.51(0.81)$ & $0.029(0.06)$ & $0.260(0.053)$ \\
Sublethal toxic effect & $r_{3}$ & $0.016(0.005)$ & $1.98(0.5)$ & $1.18(0.22)$ \\
& $\mathrm{F}_{\mathrm{a} 1}, \mathrm{~F}_{\mathrm{a} 2}$ & $0.412(0.06)$ & $0.592(0.03)$ & $0.904(0.2)$ \\
\hline
\end{tabular}


Table 4

The toxic effects of the petroleum hydrocarbon for various endpoints $\left(\mathrm{mg} \mathrm{L}^{-1}\right)$.

\begin{tabular}{|c|c|c|c|c|c|c|c|}
\hline \multirow[b]{2}{*}{ Algal Species } & \multirow[b]{2}{*}{ Endpoints } & \multicolumn{3}{|l|}{ NDEC } & \multicolumn{3}{|l|}{ TCPE } \\
\hline & & Mean & $\mathrm{Cl}_{95}$ & $R^{2}$ & Mean & $\mathrm{Cl}_{95}$ & $R^{2}$ \\
\hline \multirow[t]{2}{*}{ Platymonas helgolandica var. tsingtaoensis } & $\mathrm{K}_{1}$ & 0.056 & $0.054-0.058$ & 0.99 & & & \\
\hline & $r_{1}$ & 0.233 & $0.208-0.258$ & 0.99 & & & \\
\hline \multirow[t]{2}{*}{ Isochrysis galbana } & $\mathrm{K}_{2}$ & 0.331 & $0.327-0.335$ & 0.97 & & & \\
\hline & $r_{2}$ & 0.260 & $0.218-0.302$ & 0.99 & & & \\
\hline \multirow[t]{2}{*}{ Brachionus plicatilis } & $r_{3}$ & 1.180 & $1.004-1.356$ & 0.98 & & & \\
\hline & $\mathrm{F}_{\mathrm{a}}$ & 0.904 & $0.744-1.064$ & 0.99 & & & \\
\hline Ecosysterm & Equilibrium point & & & & 0.376 & $0.323-0.415$ & 0.9 \\
\hline
\end{tabular}

(Fig. 8). The parameters of the toxic effect sub-model for the customized ecosystem models are summarized in Table 3. According to model calculations, the densities of $B$. plicatilis decreased when exposed to petroleum hydrocarbon concentrations $>1.18 \mathrm{mg} \mathrm{L}^{-1}$, and the increase of mortality rate $\left(r_{3}\right)$ with petroleum hydrocarbon concentrations was found to be the main contributor to these observed patterns. As such, the calculated densities of P. helgolandica var. tsingtaoensis and I. galbana increased when exposed to petroleum hydrocarbon concentrations $>0.9 \mathrm{mg} \mathrm{L}{ }^{-1}$, at which point $\mathrm{Fa}_{1}$ and $\mathrm{Fa}_{2}$ began to decrease, and the decrease in the filtration rate was inferred to contribute to the increased densities of $P$. helgolandica var. tsingtaoensis and I. galbana. Although $r_{1}$ and $r_{2}$ decreased when petroleum hydrocarbon concentrations were $>0.26 \mathrm{mg} \mathrm{L}^{-1}$ (Table 3), the densities of $P$. helgolandica var. tsingtaoensis and I. galbana remained constant until the petroleum hydrocarbon concentrations were $>0.9 \mathrm{mg} \mathrm{L}^{-1}$. For example, at $4 \mathrm{mg} \mathrm{L}^{-1}$ petroleum hydrocarbon levels, the modified Weibull function indicated a $14.9 \%$ decrease in $r_{1}$, a $24.7 \%$ decrease in $r_{2}$, a $42.2 \%$ decrease in the filtration rate coefficient, and a $68.8 \%$ increase in $\mathrm{K}_{3}$. However, at the same petroleum hydrocarbon concentration, the simplified plankton ecosystem model predicted an $84.4 \%$ increase in densities of $P$. helgolandica var. tsingtaoensis, a $63.0 \%$ increase in densities of I. galbana, and a $20.2 \%$ decrease in rotifer densities, with corresponding changes observed in the experimental data. Therefore, the grazing rate increased by $>50 \%$. As such, the reduced filtration rate and rotifer grazing pressure might explain the increased densities of $P$. helgolandica var. tsingtaoensis and $I$. galbana. Similarly, the decrease in zooplankton biomass might result from the increased zooplankton grazing rate and decreased survival rate. A reduction in the toxic effects of pyrene on Daphnia magna (a small, planktonic crustacean) when combined with predation and competition from rotifers has been observed previously (Viaene et al., 2015), which was attributed to differences in the population structure of $D$. magna and inhibition in the feeding rate of predators. The combination of rotifer competition and exposure to the fungicide carbendazim led to increasing abundances of $D$. magna at all life stages in comparison with the competition controls and was related to the superior grazing capacity of $D$. magna versus rotifers and the uptake of rotifers by $D$. magna in food limiting conditions (Arco et al., 2015). These results indicate that, although the plankton densities in the single-species toxicity test decreased as the toxicant concentrations increased, the densities would not necessarily decrease within a food web owing to their dependencies on ecological interactions.

\subsection{Threshold concentration of petroleum hydrocarbons}

During the Monte Carlo simulation, the plankton ecosystem model was executed to calculate a TCPE of $0.376 \mathrm{mg} \mathrm{L}^{-1}$ for petroleum hydrocarbons with a $95 \%$ confidence interval of $0.323-0.415 \mathrm{mg} \mathrm{L}^{-1}$. However, the single-species toxicity model predicted minimal NDEC values of $0.056 \mathrm{mg} \mathrm{L}^{-1}, 0.260 \mathrm{mg} \mathrm{L}^{-1}$, and $0.904 \mathrm{mg} \mathrm{L}^{-1}$ for P. helgolandica var. tsingtaoensis, I. galbana, and B. plicatilis, respectively (Table 4). Thus, the TCPE results differed significantly from the NDEC values derived from the single-species toxicity model. Although the NDEC value obtained with endpoint $\mathrm{K}_{1}$ in the single-species toxicity test was the smallest NDEC value, it was not the threshold concentration for the simplified plankton ecosystem. Owing to the insensitivity of $\mathrm{K}_{1}$, this did not result in excursion from the equilibrium point in the simplified plankton ecological model. Fa was the most sensitive parameter in the simplified plankton ecological model; however, the NDEC value calculated using this parameter was $>0.904 \mathrm{mg} \mathrm{L}^{-1}$. $r_{1}$ was a highly sensitive endpoint of the pollutant in the single-species toxicity test, yielding an NDEC value of only $0.233 \mathrm{mg} \mathrm{L}^{-1}$, but was less influential to the excursion about the equilibrium point. These results indicate that the endpoints that were sensitive to the pollutants in the single-species toxicity tests were not necessarily the sensitive parameters in the plankton ecosystem. Thus, owing to the different sensitivities of the parameters, the minimum no-effect concentration determined with the sensitivity endpoints in the single-species toxicity test was not necessarily the threshold concentration causing the excursion from the equilibrium point in the simplified plankton ecological model.

In this study, the NDEC derived from the single-species toxicity test was more protective than TCPE. Using the SSD method, a predicted noeffect concentration (PNEC, significance level 5\%) of $0.076 \mathrm{mg} \mathrm{L}^{-1}$ was derived from the single-species toxicity test data collected in literature (Table 5) and those calculated in this study (Table 4), which was also lower than TCPE. The results from this experiment indicate that interspecies competition and grazing reduced the toxic effect of petroleum hydrocarbons at the community level, with similar studies on this topic also being reported (Arco et al., 2015; Viaene et al., 2015).

Table 5

The collected NOEC of petroleum hydrocarbon for single species used in Species Sensitivity Distribution.

\begin{tabular}{|c|c|c|c|}
\hline Species & Endpoints & $\operatorname{NOEC}\left(\mathrm{mg} \mathrm{L}^{-1}\right)$ & Reference \\
\hline Moina mongolica & Growth rate & 4.7 & Lu and $\mathrm{He}(2000)$ \\
\hline Ruditapes philippinarum & Odours & 25 & Jiang et al. (2006) \\
\hline Brachydanio rerio & Survival rate & 45 & Zheng et al. (2014) \\
\hline Isochrysis galbana & Cell density & 0.5 & Zhang (2013) \\
\hline Scrippsiella trochoidea & Uptake rate of nutrients & 8.25 & Wang et al. (2013) \\
\hline Skeleton costatum & Cell density & 1.96 & Zhang et al. (2002) \\
\hline Pheodactylum tricornutum & Cell density & 1.05 & Zhang et al. (2002) \\
\hline Nitzschia closterium f. minutissima & Chlorophyll-a & 0.98 & Ma (2013) \\
\hline Nitzschia longissima & Chlorophyll-a & 1.21 & Huang et al. (2011) \\
\hline Hemiceutrotus Pulcherrimus & Fertilization rate of eggs & 0.5 & $\operatorname{Lv}(2009)$ \\
\hline
\end{tabular}


Contrary to observations in the present study, species interactions have been found to result in greater toxic effects of pollutants (Foit et al., 2012; Gergs et al., 2013). These findings highlight the complexity of the impacts of ecological interactions on the sensitivity of populations together with the toxic effects of the pollutants. Realistic tools with ecological relevance are required to characterize and assess the response of populations to pollutants in a community. The complex ecosystem experiments are more relevant to the ecology of realistic marine ecosystems, but they suffer from poor reproducibility and difficulty in validating the predicated results with experiment data (Carpenter, 1989; Meng et al., 2009).

The community in our experiment was composed of only two species of phytoplankton and one species of zooplankton, which was easily manipulated and reliably reproduced. It is recognized that phytoplankton are the base of the marine food web and zooplankton an important link in the food chain of marine ecosystems and, in combination, they are the main constituents of ocean ecosystems. The interspecies competition and grazing in the plankton also showed the representative ecological relationships occurring in marine organisms (Chang and $\mathrm{Ge}$, 2001; Lalli and Parsons, 1993). The selected species interactions are relevant to entire marine ecosystems. The model proposed in the present study was a three-species coupling model with only a few parameters and, thus, was easily verified. Moreover, a coupling model using only three species possesses a positive asymptotic equilibrium point under certain conditions, which can be used as the endpoint in the calculation of threshold concentrations for pollutants such as petroleum hydrocarbons. This proposed indicator incorporated interspecies interactions and integrated multiple effects into a single measurement to characterize the ecotoxicological effects of the plankton community, which was a response to concern over the impacts of ecological interactions on ecological risk assessments of pollutants. The model proposed in this study provides an improved method for understanding mathematically the key ecological relationships in realistic marine ecosystems and for better predictions of communities' responses to pollutants than can be obtained through extrapolation of single-species effect data.

However, our study is, at most, an advance on the use of SSDs based on single-species tests. The method introduced in this study is only useful for a community where three species can co-exist and inapplicable if there is no equilibrium point in a community, such as when one species dominates and the other/s become extinct. The relevance to the ecology for the performed ecosystem experiment is also limited as only three species were used. The toxic effects of pollutants in complex communities may be less pronounced because of greater ecological interactions and species redundancies. Therefore, indirect effects might have a great impact on ecotoxicological effects in complex communities; it is also possible that the NDEC from the sensitive single species will be over protected for some pollutants. This also demonstrates that the toxic ecological effects at the community-level are determined not only by the sensitive species, but also by the ecological relationships among the species.

\section{Conclusions}

The performed experiments in this study examined the toxic effects of petroleum hydrocarbons on the densities of three plankton species in a customized ecosystem, and showed that interspecies competition and grazing interacted antagonistically with petroleum hydrocarbons when the toxic effect of petroleum hydrocarbons on algae was pronounced. The three-population ecological model constructed in the present study was conducted to calculate a TCPE of $0.376 \mathrm{mg} \mathrm{L}^{-1}$ for petroleum hydrocarbons at the community level, which was higher than the NDEC of $0.056 \mathrm{mg} \mathrm{L}^{-1}$ derived from the single-species toxicity test and the PNEC of $0.076 \mathrm{mg} \mathrm{L}^{-1}$ calculated from the SSD. This is an example of antagonism between interspecies interactions and pollutants toxicity. Nevertheless, previous reports indicated that species interactions resulted in synergistic effects. These findings highlight the complexity of the impacts of ecological interactions on populations and communities together with the toxic effects of pollutants and the need to consider these toxic effects not only at an individual or population level but also at the community level when assessing the risk of pollutants for communities. A similar simplified experiment in combination with the three-population ecological model proposed in this study could assist with integrating interspecies interactions to assess ecological risk of pollutants and to account for the patterns observed in experiments with ecological interactions.

\section{Acknowledgements}

This study was supported by the Natural Science Foundation of the Jiangsu Higher Education Institutions of China (Project No. 14KJB170016), the Natural Science Foundation of Jiangsu Province, China (Project No. BK20141478), National Science and Technology Major Project of the Ministry of Science and Technology of China (Project No. 2012ZX07501) and the Priority Academic Program Development of Jiangsu Higher Education Institutions (PAPD).

\section{Appendix A. Supplementary data}

Supplementary data to this article can be found online at http://dx. doi.org/10.1016/j.scitotenv.2016.06.164.

\section{References}

Arco, A.I.D., Rico, A., Brink, P.J.V.D., 2015. Effects of intra- and interspecific competition on the sensitivity of Daphnia magna populations to the fungicide carbendazim [J]. Ecotoxicology 24, 1362-1371.

ASTM E1440-91, 2012. Standard Guide for Acute Toxicity Test with the Rotifer Brachionus. ASTM International [S], West Conshohocken, PA (2012, www.astm.org).

Carpenter, S.R., 1989. Replication and treatment strength in whole-lake experiments [J]. Ecology 70 (2), 453-463.

Chang, J., Ge, Y., 2001. Ecology [M]. Zhejiang University Press, Hangzhou.

Chapman, P.M., Wang, F.Y., Janssen, C.R., Goulet, R.R., Kamunde, C.N., 2003. Conducting ecological risk assessments of inorganic metals and metalloids: current status [J]. Hum. Ecol. Risk. Assess. 9, 641-697.

Chen, Y., Yan, T., Zhou, M.J., 2007. The effects of Prorocentrum donghaiense and Alexandrium catenella on the material transfer in a simulated marine food chain [J]. Acta Ecol. Sin. 27, 3964-3972.

European Commission, 2003. Technical Guidance Document on Risk Assessment. ([S]. http://europa.eu.int).

Fang, K., Tang, X., Zhang, J., Wang, Y., 2013. Effects of different species and densities of marine bait microalgae on feeding of rotifer Brachionus plicatilis neonates [J]. Mar. Environ. Sci. 32 (4), 497-501.

Feng, L., 2006. Effects of UV-B Radiation on Experimental Population Dynamics and Interspecific Competition of Two Species of Marine Rotifers (B. plicatilis \& B. urceus) [D]. Ocean University of China, Qingdao.

Fleeger, J.W., Carman, K.R., Nisbet, R.M., 2003. Indirect effects of contaminants in aquatic ecosystems [J]. Sci. Total Environ. 317, 207-233.

Foit, K., Kaske, O., Wahrendorf, D.S., Duquesne, S., Liess, M., 2012. Automated nanocosms test systems to assess the effects of stressors on two interacting populations [J]. Aquat. Toxicol. 109 (3), 243-249 (2012).

Frost, B.W., 1972. Effects of size and concentration of food particles on the feeding behavior of the marine planktonic copepod Calanus pacificus [J]. Limnol. Oceanogr. 17, 805-815.

General Administration of Quality Supervision, Inspection and Quarantine of China (AQSIQ), 2008a. GB/T 21805-2008, Chemicals-Alga Growth Inhibition Test [S]. Standards Press of China, Beijing.

Gergs, A., Zenker, A., Grimm, V., Preuss, T.G., 2013. Chemical and natural stressors combined: from cryptic effects to population extinction [J]. Sci. Report. 3 (7454), 400 (2013)

Guillard, R., Ryther, J., 1962. Studies of marine planktonic diatoms. 1. Cyclotella nana, Hustedt and Detonula confervacea (Cleve) [J]. Can. J. Microbiol. 8, 229-237.

Hao, W., Wang, Y., Tang, X, 2008. Interactions between two marine microalgaes: Amphidinium carterae Hulburt and Platymonas helgolandica var. tsingtaoensis in under controlled laboratory co-culture [J]. Acta Sci. Nat. Univ. Sunyatseni 47 (Z1), 98-105.

Huang, Y., Chen, Q., Zeng, J., Jiang, Z., 2011. The impact of oil pollution on marine phytoplankton community growth change [J]. Acta Ecol. Sin. 31 (2), 513-521.

Jiang, C., Qiao, Q., Cai, Y., Xu, J., 2006. Kinetic features and threshold value of petroleum hydrocarbons for Ruditapes philippinarum [J]. Mar. Fish. 28 (4), 314-320.

Laender, F.D., Schamphelaere, K.A.C.D., Vanrolleghem, P.A., Janssen, C.R., 2008. Comparison of different toxic effect sub-models in ecosystem modelling used for ecological effect assessments and water quality standard setting [J]. Ecotoxicol. Environ. Saf. 69, 13-23. 
Lalli, C.M., Parsons, T.R., 1993. Biological Oceanography: An Introduction [M]. Pergamon Press, Oxford.

Lau, E.T.C., Yung, M.M.N., Karraker, N.E., Leung, K.M.Y., 2013. Is an assessment factor of 10 appropriate to account for the variation in chemical toxicity to freshwater ectotherms under different thermal conditions? [J]. Environ. Sci. Pollut. Res. Int. 21 (1), 95-104

Li, H., Wang, J.T., 2012. Inter-specific competition between Prorocentrum donghaiense and Skeletonema costatum [J]. Acta Ecol. Sin. 32 (4), 1115-1123.

Li, L., Zhu, X.M., Wu, H.Y., 2011. Feeding of rotifer Brachionus plicatilis enriched with microalgae [J]. Chin. J. Ecol. 30 (9), 2019-2025.

Lu, H., He, Z., 2000. Toxicity of crude oil and refined oils from Daqing to Moina mongolica Dady [J]. J. Dalian Fish. Univ. 15 (3), 169-174.

Lv, F., 2009. Study on Toxic Effect and Molecular Mechanism of Petroleum Hydrocarbon Pollution to Hemiceutrotus pulcherrimus [D]. Dalian Maritime University, Dalian.

Ma, S., 2013. Toxicity of Crude Oil and Four Kinds of Dispersants to P. helgolandica and N. closterium [D]. Ocean University of China, Oingdao.

Meng, W., Yan, Z.G., Liu, Z.T., 2009. Analysis of guideline s for deriving water quality criteria in the United States and construction of related criteria in China [J]. Res. Environ. Sci. 22 (7), 757-761.

OECD, 2002. Detailed Review Paper on Aquatic Testing Methods for Pesticides and Industrial Chemicals, OECD Series on Testing and Assessment, No. 11 [R]. OECD Publishing, Paris.

Rico, A., Van den Brink, P.J., Gylstra, R., Focks, A., Brock, T.C.M., 2016. Developing ecological scenarios for the prospective aquatic risk assessment of pesticides [J]. Integr. Environ. Assess. Manag. 84 (n2), 218-232.

Snell, T.W., Janssen, C.R., 1995. Rotifers in ecotoxicology: a review [J]. Hydrobiologia 313/ 314, 231-247.

Steele, J.H., 1974. The Structure of Marine Ecosystems [M]. Blackwell Scientific Publication, Oxford London.

Sun, Y., Sun, L., Wang, C., 2005. Study on the growth of Isochrysis galbana [J]. Mar. Sci. Bull. 24 (3), 92-96.

Tang, Q.S., 1999. Strategies of research on marine food web and trophodynamics between high trophic levels [J]. Mar. Fish. Res. 20 (2), 1-6.

The International Tanker Owners Pollution Federation (ITOPF), 2013F. Oil tanker spill statistics 2013 [EB/OL]. http://www.itopf.com/knowledge-resources/data-statistics/ statistics (Accessed 26 June 2014)
Van, D.H.N., 2004. Current issues in statistics and models for ecotoxicological risk assessment [J]. Acta Biotheor. 53, 201-217.

Viaene, K.P.J., De Laender, F., Rico, A., Van den Brink, P.J., Di Guardo, A., Morselli, M., Janssen, C.R., 2015. Species interactions and chemical stress: combined effects of intraspecific and interspecific interactions and pyrene on Daphnia magna population dynamics [J]. Environ. Toxicol. Chem. 34 (8), 1751-1759.

Volterra, V., 1926. Fluctuations in the abundance of a species considered mathematically [J]. Nature 118, 558-560.

Wang, C., Liang, S., Li, Y., Li, K., Wang, X., 2015a. The spatial distribution of dissolved and particulate heavy metals and their response to land-based inputs and tides in a semienclosed industrial embayment: Jiaozhou Bay, China [J]. Environ. Sci. Pollut. Res. 22, 10480-10495.

Wang, Z.L., Qu, N., Dai, F.F., 2010. Increasing pattern of phytoplankton biomass with species richness and tests of sampling and complementary effects [J]. Chin. J. Appl. Ecol. 21 (8), 2148-2153.

Wang, C.Y., Wang, X.L., Su, R.G., Liang, S.K., Yang, S.P., 2011. No detected toxic concentrations in in situ algal growth inhibition tests - a convenient approach to aquatic ecotoxicology [J]. Ecotoxicol. Environ. Saf. 74, 225-229.

Wang, C., Zhang, Y., Li, H., Xing, W., Yu, H., 2015b. The effects of petroleum hydrocarbons on algae can be reversed in the presence of a primary consumer [J]. Bull. Environ. Contam. Toxicol. 95, 344-349.

Wang, J., Zhao, W., Li, X., Li, H., 2013. Effects of petroleum hydrocarbon on the uptake of nutrients by marine phytoplankton [J]. Ocean. Et Limnologia Sin. 44 (1), 43-48.

Wei, Y.M., 2009. Analysis and Simulation of the Lotka-Volterra Predator-Prey Model [D]. Minzu University of China, Beijing.

Xu, D., 2008. Combined Effcet of Interspecies, Feeding and UV-B Stress on Experimental Population Dynamics of Skeletonema costatum [D]. Ocean University of China Qingdao.

Zhang, Y., 2013. Toxic Effects and Mechanisms of Petroleum Hydrocarbon on Marine Microalgae [D]. Ocean University of China, Qingdao.

Zhang, L., Wang, X., Han, X., Zhu, C., Shi, X., Jiang, F., Yang, R., 2002. Effects of petroleum hydrocarbon on the growth of marine algae: experiment versus model [J]. J. Ocean Univ. Qingdao 32 (5), 804-810.

Zheng, X., Li, Y., Bao, M., He, R., Liu, S., Shang, Y., 2014. Acute toxic effect of some petroleum hydrocarbons on brachydanio rerio [J]. Period. Ocean Univ. Chin. 44 (6), 67-71. 